\title{
Immunosuppressive Treatment in Multifocal Motor Neuropathy
}

\author{
Eva L. Feldman, MD, PhD, Mark B. Bromberg, MD, PhD, \\ James W. Albers, MD, PhD, and Alan Pestronk, MD*
}

\begin{abstract}
We report the results of immunosuppressive treatments of 13 patients with multifocal motor neuropathy and elevated titers of serum antibodies to the GM1 ganglioside. All patients failed to respond to oral prednisone. There was no clinical response in 4 patients treated with plasma exchange. Nine patients received cyclophosphamide, with clinical improvement and fall in antibody titers in 8 . In 3 patients, cyclophosphamide was discontinued with ensuing clinical relapse and rise in the titers of serum anti-GMl antibodies. These patients provide further evidence for the efficacy of cyclophosphamide therapy in patients with multifocal motor neuropathy.
\end{abstract}

Feldman EL, Bromberg MB, Albers JW, Pestronk A. Immunosuppressive treatment in multifocal motor neuropathy. Ann Neurol 1991;30:397-401

Lower motor neuron syndromes can be divided into clinical subsets based on the patterns of weakness, electrodiagnostic abnormalities, and serum antiglycolipid antibody activity [1]. One such syndrome, multifocal motor neuropathy (MMN), is characterized by distal, asymmetrical weakness and conduction block on motor but not sensory axons [1-4]. High titers of serum antibodies to GM1 ganglioside are common in this syndrome $[1,2]$ and in acquired lower motor neuron syndromes in general $[1,5-9]$.

Individual patient reports suggest that MMN may respond to immunotherapy [2]. Cytotoxic medications such as cyclophosphamide may be useful in producing clinical improvement, that is, an increase in strength $[2,3]$. In this study, we report our retrospective experience with the treatment of a series of 13 patients with a diagnosis of MMN. Our results show that prednisone treatment, even in high doses, is not often associated with clinical benefit in patients with MMN. In contrast, improvement in strength commonly occurs within 3 to 6 months after institution of cyclophosphamide therapy. Further, there is usually a correlation between clinical improvement and reduction of titers of antiGM1 antibodies.

\section{Patients and Methods \\ Patients}

We studied the effects of immunosuppressive therapy in patients with MMN defined by clinical, electrophysiological, and immunological criteria (see Results). The features of 9 of these patients (Patients 1, 2, 6, 7, 9-13) have been outlined previously [1]. Three improved after cyclophosphamide therapy in that study. The patients with MMN reported here are all those examined and treated by us between January 1987 and June 1990.

\section{Electrodiagnostic Studies}

Electrodiagnostic studies were performed under standard conditions with attention to maintenance of skin temperature above $32^{\circ} \mathrm{C}$. Conduction block in motor nerves was defined as a reduction in the ratio of proximal-to-distal compound muscle action potential (CMAP) amplitude to $<0.70$ when the ratio of the proximal-to-distal negative peak duration was $<1.15[10-12]$. Abnormal temporal dispersion with or without conduction block was considered present when the ratio of proximal-to-negative peak duration was $>1.15$. Potential sites of nerve entrapment were taken into consideration when evaluating conduction block.

\section{Determination of Serum Antibodies}

Antibodies to gangliosides were assayed by enzyme-linked immunosorbent assay (ELISA) methodology as described previously [1]. Briefly, $400 \mathrm{ng}$ of GM1 (Sigma Chemical, St Louis, MO) was adsorbed to wells of ELISA plates before the addition of test serums at dilutions of 1:50 to $1: 100,000$ for 5 hours at $4^{\circ} \mathrm{C}$. Horseradish peroxidase-linked specific goat anti-human IgM or IgG was then added overnight, and color was developed for approximately 30 minutes until a standard positive control reached an optical density (OD) of $1.0 \mathrm{at} 450 \mathrm{~nm}$. Serum ODs were determined and titers calculated from a linear range of dilutions. Titers of serum IgM agonist GM1 ganglioside $\geq 350$ are more than 4 SDs above the mean value in panels of normal control subjects [13]. A spontaneous fall of more than $60 \%$ in titers of IgM
From the Department of Neurology, University of Michigan, Ann Arbor, MI, and "the Department of Neurology, Washington University School of Medicine, St Lowis, MO.
Received Dec 18, 1990, and in revised form Mar 12, 1991. Accepted for publication Mar 18, 1991.

Address correspondence to Dr Feldman, $1120 \mathrm{C}$ Neuroscience Laboratory Building, 1103 E. Huron Street, Ann Arbor, MI 48109-1687. 
anti-GM1 antibodies occurs in less than $5 \%$ of untreated patients $\{14\}$.

\section{Quantitation of Motor Function}

Strength testing was quantitated using the Medical Research Council (MRC) rating scale. MRC values were determined on each side for the following six muscles: deltoids, biceps, interossei, iliopsoas, quadriceps, and anterior tibialis. A patient was judged improved if strength increased in weak muscles of at least one extremity an average of one or more MRC grades. MRC values were also averaged for each patient, giving a strength index that could be followed over time.

\section{Selective Patient Reports \\ Patient 6}

A 63-year-old woman presented in 1985 with a 10year history of progressive weakness. Bilateral thumb weakness was followed 5 years later by left finger extensor weakness, which progressed slowly to involve intrinsic hand muscles bilaterally. Neurological examination revealed asymmetrical atrophy and weakness in the upper extremities with greater involvement distally. Lower extremity strength was normal. Deep tendon reflexes were preserved. Sensory examination was normal. She was treated for 3 years with oral prednisone, up to $60 \mathrm{mg}$ per day, but weakness progressed to include lower extremities and she became areflexic. Nine therapeutic plasma exchanges and intravenous methylprednisone ( $1 \mathrm{gm} \times 3$ treatments) did not interrupt her decline. By the end of 1987 , she was quadriplegic and was begun on intravenous cyclophosphamide ( $3 \mathrm{gm} / \mathrm{M}^{2}$ ), followed 1 month later by oral cyclophosphamide ( $2 \mathrm{mg} / \mathrm{kg} /$ day). Within 4 months she began to regain strength, and after 6 months was ambulatory and had full use of her hands, at which time cyclophosphamide was discontinued. She remained stable for 1 year, but then noticed the return of thumb weakness. Oral cyclophosphamide ( $2 \mathrm{mg} / \mathrm{kg} /$ day) was restarted and within 1 month her strength returned.

Serum and urine immunofixation patterns and cerebrospinal fluid protein were normal. A sural nerve biopsy was normal. IgM anti-GM1 titer was 480 units before cyclophosphamide therapy and fell to 0 units over 15 months. As the antibody titer rose to 195 units, she had an exacerbation, and as the titer fell to 68 units with treatment, she went into remission. Sensory nerve conduction studies were normal. Motor nerve conduction studies showed conduction block with varying degrees of abnormal temporal dispersion (Fig 1).

\section{Patient 5}

A 35-year-old man presented with 1.5 years of weakness first affecting the grip of his right hand, then weakness of his right arm and left leg. He had no sensory complaints. Neurological examination revealed atrophy and weakness of the right hand and left leg. Re-

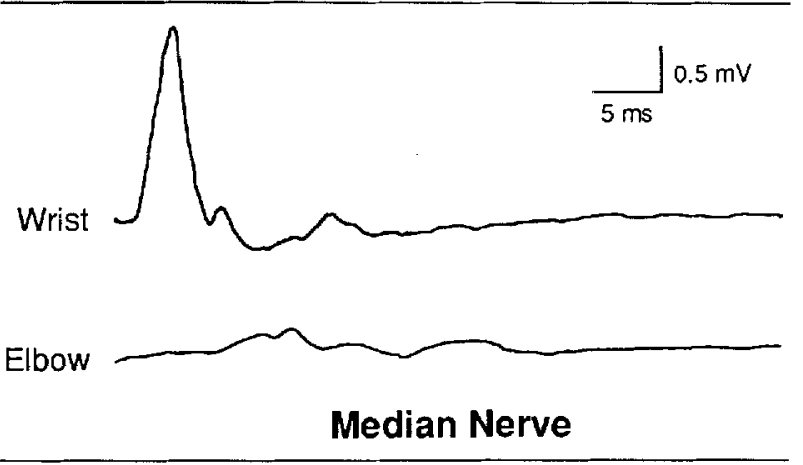

Fig 1. Median motor conduction study of Patient 6, demonstrating partial conduction block. The area of the median nerve response on elbow stimulation is $<30 \%$ of the response on wrist stimulation.

flexes were present and normal in the left arm and left knee, but decreased in the right arm and were absent at the left ankle. Sensory examination was normal. The patient was begun on prednisone, $60 \mathrm{mg}$ per day for 3 months, but his weakness progressed. Intravenous cyclophosphamide $\left(3 \mathrm{gm} / \mathrm{M}^{2}\right)$, followed by oral cyclophosphamide ( $2 \mathrm{mg} / \mathrm{kg} / \mathrm{day}$ ), was started. Improvement in strength occurred by 6 weeks and he has returned to work. His neurological examination has remained normal while he takes oral cyclophosphamide.

Serum and urine immunofixation patterns and cerebrospinal fluid protein were normal. Sural nerve biopsy was normal. IgM GM1 ganglioside titer was 398 units before cyclophosphamide therapy and fell to 50 units over 4 months. Sensory nerve conduction studies were normal. Motor nerve conduction studies showed conduction block.

\section{Results}

The clinical and electrophysiological profiles of the 13 patients are presented in Table 1 . There were 9 men and 4 women, ages 30 to 66 years. All 13 parients had asymmetrical weakness, with prominent upper extremity involvement and a normal sensory examination. Reflexes were normal in 6 patients, decreased in 4 patients, and absent in 3 patients. Duration of symptoms ranged from 1 to 20 years. Eight patients had normal motor nerve conduction velocities, and 5 had mild slowing. All 13 patients had normal sensory-evoked amplitudes and conduction velocities. The striking finding in each patient was prominent multifocal motor conduction block with varying degrees of abnormal temporal dispersion, especially in the upper extremities (see Fig 1). Serum anti-GM1 antibody titers were high $(\geq 350)$ in each of the patients.

All patients were treated with high-dose oral prednisone, many for extended periods, with no clinical response. In the 4 patients treated with only prednisone (Patients 1-4) there was no consistent change in anti- 


\begin{tabular}{|c|c|c|c|c|c|c|}
\hline \multirow[b]{2}{*}{ Patient } & \multirow[b]{2}{*}{ Age $(y r) / S e x$} & \multirow{2}{*}{$\begin{array}{l}\text { Duration of } \\
\text { Symptoms (yr) }\end{array}$} & \multirow{2}{*}{$\begin{array}{l}\text { Motor } \\
\text { Distribution }^{2}\end{array}$} & \multirow{2}{*}{$\begin{array}{l}\text { Tendon } \\
\text { Reflexes }\end{array}$} & \multicolumn{2}{|c|}{ Motor Conduction Studies } \\
\hline & & & & & Velocity & Nerves with Block \\
\hline 1 & $69 / \mathrm{M}$ & 3 & $\mathrm{UE}>\mathrm{LF}$ & $t^{a}$ & \pm slow & $\mathrm{U}$ \\
\hline 2 & $62 / \mathrm{M}$ & 5 & UE & + & WNL & $\mathrm{U}+\mathrm{M}$ \\
\hline 3 & $47 / \mathrm{M}$ & 2 & $\mathrm{UE}>\mathrm{LE}$ & 0 & $\begin{array}{l}\text { slow } M \text {, otherwise } \\
\text { WNL }\end{array}$ & $\mathrm{U}+\mathrm{M}$ \\
\hline 4 & $66 / \mathrm{F}$ & 8 & $\mathrm{UE}+\mathrm{LE}$ & 0 & WNL & $\mathrm{U}+\mathrm{M}$ \\
\hline 5 & $35 / \mathrm{M}$ & 1 & $\mathrm{UE}+\mathrm{LE}$ & $+{ }^{a}$ & WNL & $\mathrm{U}+\mathrm{M}$ \\
\hline 6 & $63 / \mathrm{F}$ & 10 & $\mathrm{UE}>\mathrm{LE}$ & $+^{\mathrm{a}}$ & \pm slow & $\mathrm{U}+\mathrm{M}$ \\
\hline 7 & $55 / \mathrm{M}$ & 3 & $\mathrm{UE}>\mathrm{LE}$ & $+b$ & WNL & $\mathrm{U}$ \\
\hline 8 & $48 / \mathrm{F}$ & 5 & $\mathrm{UE}>\mathrm{LE}$ & + & $\begin{array}{l}\text { slow } M \text {, otherwise } \\
\text { WNL }\end{array}$ & $\mathrm{U}+\mathrm{M}$ \\
\hline 9 & $30 / \mathrm{M}$ & 3 & UE (left only) & + & $\begin{array}{l}\text { slow U, otherwise } \\
\text { WNL }\end{array}$ & $\mathrm{U}+\mathrm{M}$ \\
\hline 10 & $43 / \mathrm{F}$ & 1 & UE & + & \pm slow & $\mathrm{U}+\mathrm{M}$ \\
\hline 11 & $51 / \mathrm{M}$ & 1 & UE & + & \pm slow & $U+M$ \\
\hline 12 & $61 / \mathrm{M}$ & 20 & $\mathrm{UE}>\mathrm{LE}$ & 0 & WNL & multifocal \\
\hline 13 & $32 / \mathrm{M}$ & 3 & $\mathrm{UE}+\mathrm{LE}$ & $+^{a}$ & \pm slow & $\mathbf{U}+\mathbf{M}$ \\
\hline
\end{tabular}

absent ankle reflexes.

${ }^{\text {b }}$ Reduced in areas of severe weakness in arms.

$\mathrm{UE}=$ upper extremity; $\mathrm{LE}=$ lower extremity; $\mathrm{WNL}=$ within normal limits; $\mathrm{U}=$ ulnar; $\mathrm{M}=$ median; \pm slow $=$ two or more motor nerve conduction velocities at or within $10 \%$ of the lower limits of normal.

GM1 antibody titers. Titers increased in 2 patients and decreased in the 2 others. Four patients received plasma exchange without clinical benefit.

Nine patients received intravenous and follow-up oral cyclophosphamide treatment [2], with the major side effects of mild leukopenia and alopecia. Eight showed clinical improvement of at least one full grade on the MRC scale during the first 2 to 5 months of treatment. This was usually paralleled by reduced serum GM1 antibody titers, which decreased to an average of $67 \%$ of initial levels (Table 2). The percent change in titer, and not the absolute level of titer, correlated with changes in clinical course. Three patients relapsed after cyclophosphamide treatment was stopped. In all, anti-GM1 titers had risen toward pretreatment values. Two of these patients were retreated with cyclophosphamide with subsequent improvement in strength.

Sequential electrophysiological studies were performed on Patient 6. The progression of weakness was related to a progressive decline in the CMAP amplitude. The proximal/distal amplitude ratio was a poor predictor of strength because a disproportionate increase in the distal amplitude could result in a decreased ratio at a time that both amplitudes and strength were increasing (Fig 2).

\section{Discussion}

In this study, we followed the clinical status of 13 patients with MMN who were treated with immunosup- pressive therapy. Our results suggest that prednisone is rarely an effective treatment for this syndrome. None of our patients with MMN improved during periods of treatment with prednisone alone. The 4 patients who were never treated with a cytotoxic medication all showed slow, continued progression during the 1 to 3 years of observation. The pattern of prednisone resistance of $\mathrm{MMN}$ is consistent with most reports of patients with asymmetrical motor neuropathy and motor conduction block $[2,3]$.

In contrast to the lack of response to prednisone, cyclophosphamide treatment was associated with improved strength in 8 of 9 patients with MMN. Improvement began in the 8 patients after 2 to 5 months of treatment. The eventual degree of increased strength in these patients was at least one MRC grade. One patient (Patient 6), who was initially quadriplegic, improved to normal strength in most muscle groups. In some patients, maintenance of immunosuppressive medications appeared necessary for continued control of the disease process. Three patients developed recurrent weakness 6 to 12 months after cyclophosphamide treatment was discontinued. Two of these patients were restarted on cyclophosphamide with improvement of strength. Treatment with cytotoxic medications has also been reported effective in other patients with lower motor neuron syndromes and high titers of anti-GM1 antibodies $[1,15,16]$.

These experiences suggest that cyclophosphamide treatment may be effective in inducing and maintaining 


\begin{tabular}{|c|c|c|c|c|c|c|c|}
\hline \multirow[b]{3}{*}{ Patient } & \multirow[b]{3}{*}{ Prednisone $e^{b}$} & \multicolumn{2}{|c|}{ Change in MRC Scale } & \multirow{2}{*}{\multicolumn{4}{|c|}{ Anti-GM1 Titers }} \\
\hline & & \multirow{2}{*}{$\begin{array}{l}\text { Plasma } \\
\text { Exchange }\end{array}$} & \multirow{2}{*}{$\begin{array}{l}\text { Cytotoxic } \\
\text { Medication }\end{array}$} & & & & \\
\hline & & & & Pre-Therapy & During Therapy & $\%$ Reduction & Relapse \\
\hline 1 & $0(60 \times 4 \mathrm{mo})$ & - & - & 114,250 & 60,800 & 47 & $\ldots$ \\
\hline 2 & $0(60 \times 3 \mathrm{mo})$ & - & - & 582 & 486 & 16 & $\ldots$ \\
\hline 3 & $-1(60 \times 6 \mathrm{wk})$ & - & - & 14,360 & 19,040 & -33 & $\ldots$ \\
\hline 4 & $0(50 \times 1 \mathrm{yr})$ & - & - & 370 & 720 & -94 & $\ldots$ \\
\hline 5 & $0(60 \times 3 \mathrm{mo})$ & - & +1 & 398 & 50 & 87 & $\ldots$ \\
\hline 6 & $-1(30 \times 3 y r)$ & 0 & +3 & 458 & 0 & 100 & 198 \\
\hline 7 & $0(60 \times 4 \mathrm{mo})$ & - & +1 & 204,500 & 56,080 & 73 & $\ldots$ \\
\hline 8 & $0(80 \times 4 \mathrm{mo})$ & - & +1 & 2,205 & 2,048 & 7 & . . \\
\hline 9 & $0(80 \times 5 \mathrm{mo})$ & - & +2 & 1,490 & 102 & 93 & 606 \\
\hline 10 & $-1(100 \times 6 \mathrm{mo})$ & 0 & +2 & 3,880 & 908 & 76 & $\ldots$ \\
\hline 11 & $0(100 \times 4 \mathrm{mo})$ & 0 & +2 & 1,535 & 395 & 74 & 996 \\
\hline 12 & $0(80 \times 6 \mathrm{mo})$ & 0 & 0 & 13,693 & 9,600 & 30 & $\ldots$ \\
\hline 13 & $0(60 \times 2 \mathrm{mo})$ & - & +1 & 1,570 & - & - & $\ldots$ \\
\hline
\end{tabular}

2 1 indicates loss of at least one MRC grade; 0 , no change in MRC grade; +1 indicates improvement by 1 MRC grade, +2 by 2 MRC grades, and +3 by 3 MRC grades.

${ }^{b}$ Average dose of prednisone given on a daily basis.

MRC = Medical Research Council. (-) Indicates patient did not receive therapy or anti-GM1 titer was not measured.

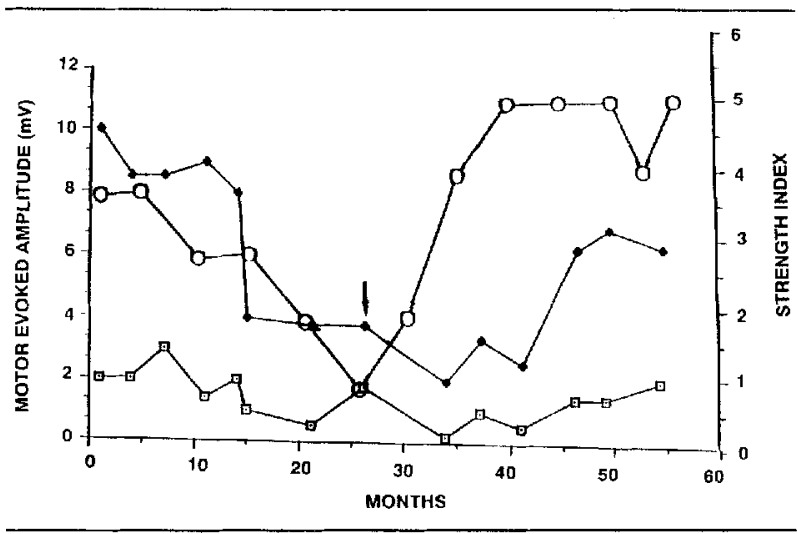

Fig 2. Relationship of changes in distal and proximal ulnar neve motor-evoked amplitude and functional status during $i m$ munosuppressive therapy in Patient 6. Arrow indicates initiation of cyclopbosphamide treatment. $(-\longrightarrow)=$ Distal ulnar motor-evoked amplitude; $(-[-)$ = proximal ulnar motorevoked amplitude; $(-\mathrm{O}-)=$ average $M R C$ strength index.

clinical remission of MMN. Spontaneous improvement is rare in patients with motor neuron disorders or motor neuropathies that are progressive for more than 1 year [1]. The percentage of parients in our study who improved after cyclophosphamide treatment, $88 \%$ (8 of 9 patients), is significantly greater $(p<0.001)$ than the $0 \%$ response to prednisone in the same patients. Overall, the clinical course was paralleled by changes in anti-GM1 antibody titers. These titers showed no consistent change during treatment with prednisone. Titers were reduced, however, by an average of $67 \%$ after cyclophosphamide therapy [14]. Most patients began to improve during the period when antibody titers fell below one-half of their initial levels. All 4 patients with improvement in strength of two or more MRC grades had a reducrion in their anti-GM1 antibody titers of $70 \%$ or more. Measurement of antiGM1 antibody titers is probably useful, not only for diagnosing MMN, but also for monitoring necessary and sufficient treatment during a trial of cyclophosphamide.

Our results provide more evidence that MMN is an immune-mediated process. The disorder differs, however, from typical chronic inflammatory demyelinating polyneuropathy (CIDP) [17, 18]. Patients with predominantly motor forms of CIDP $[19,20]$ usually have symmetrical weakness that involves proximal muscles early in the course of the disease. Although nerve conduction studies in patients with CIDP may show evidence of conduction block, there is often evidence of more diffuse demyelination of both motor and sensory axons. Changes in CIDP that occur in only a minority of patients with MMN include slowing ( $<70 \%$ of normal) of conduction velocities and prolonged distal latencies. A further difference between $M M N$ and CIDP lies in their serum antibody reactivity. High titers of IgM anti-GM1 antibodies are common in patients with MMN, but rare in patients with CIDP [1]. A final contrast between the two disorders is their response to treatment. As has been reported for the overall population of patients with CIDP, those with motor CIDP usually demonstrate increased strength within a few months after treatment with 
prednisone. This is clearly not the case for parients with MMN.

In summary, our results provide further support for the effectiveness of cyclophosphamide therapy in patients with MMN. Controlled trials would be useful to confirm this conclusion. Even if cyclophosphamide is efficacious, however, its toxicity limits the benefit:risk ratio, especially in patients with only mild disability. Trials of other medications with fewer side effects are also necessary.

Dr Feldman is supported by National Institutes of Health (NIH) Grant NS-01381. Dr Pestronk is supported by NIH Grant 1RO1A6074238 and the Muscular Dystrophy Association.

\section{References}

1. Pestronk A, Chaudhry V, Feldman EL, et al. Lower motor neuron syndromes defined by patterns of weakness, nerve conduction abnormalities and high titers of antiglycolipid antibodies. Ann Neurol 1990;27:316-326

2. Pestronk A, Comblath DR, Ilyas AA, et al. A treatable multifocal motor neuropathy with antibodies to GM1 ganglioside. Ann Neurol 1988;24:73-78

3. Parry GJ, Clarke S. Multifocal acquired demyelinating neuropathy masquerading as motor neuron disease. Muscle Nerve 1988;11:103-107

4. Krarup C, Stewart JD, Sumner AJ, et al. A syndrome of asymmetric limb weakness with motor conduction block. Neurology 1990;40:118-127

5. Nardelli E, Steck AJ, Barkas T, et al. Motor neuron syndrome and monoclonal $\mathrm{IgM}$ with antibody activity against gangliosides GM1 and GD1b. Ann Neurol 1988;23:524-528

6. Shy ME, Rowland LP, Smith T, et al. Motor neuron disease and plasma cell dyscrasia. Neurology 1986;36:1429-1436

7. Freddo L, Yu RK, Latov N, Donofrio PD, er al. Gangliosides GM1 and GDib are antigens for IgM M-protein in a patient with motor neuron disease. Neurology 1986;36:454-458
8. Sadiq SA, Thomas FP, Kilidireas $\mathrm{K}$, et al. The spectrum of neurologic disease associated with anti-GM1 antibodies. Neurology 1990;40:1067-1072

9. Salazar-Grueso EF, Routbort MJ, Martin J, et al. Polyclonal IgM anti-GM1 ganglioside antibody in patients with moror neuron disease and variants. Ann Neurol 1990;27:558-563

10. Lewis RA, Sumner AJ, Brown MJ, Asbury AK. Multifocal demyelinating neuropathy with persistent conduction block. Neurology 1982;32:958-964

11. Bradley WG, Bennett RK, Good P, Little B. Proximal chronic inflammatory polyneuropathy with multifocal conduction block. Arch Neurol 1988;45:451-455

12. Albers JW, Donofrio PD, McGonagle TK. Sequential electrodiagnostic abnormalities in acute inflammatory demyelinating polyradiculoneuropathy. Muscle Nerve 1985;8:528-539

13. Pestronk A, Adams RN, Clawson $L$, et al. Serum antibodies to GM1 ganglioside in amyotrophic lateral sclerosis. Neurology 1988;38:1457-1461

14. Pestronk A, Adams RN, Kund RW, et al. Differential effects of prednisone and cyciophosphamide on autoantibodies in human neuromuscular disorders. Neurology 1989;39:628-632

15. Latov N, Hays AP, Donofrio PD, et al. Monoclonal IgM with unique specificity to gangliosides GM1 and GD1b and to lacto$\mathrm{N}$-tetraose associated with human motor neuron disease. Neurology 1988;38:763-768

16. Shy ME, Heiman-Patterson T, Parry GJ, et al. Lower motor neuron disease in a patient with autoantibodies against Gal(B)3) GalNAc in gangliosides GMI and GDlb: improvement following immunotherapy. Neurology 1990;40:842-844

17. Dyck PJ, Lais AC, Ohta $M$, et al. Chronic inflammatory polyradiculoneuropathy. Mayo Clin Proc 1975;50:621-637

18. Barohn RJ, Kissel JT, Warmolts JR, Mendell JR. Chronic inflammatory demyelinating polytadiculoneuropathy: clinical characteristics, course, and recommendations for diagnostic criteria. Arch Neurol 1989;46:878-884

19. Van den Bergh P, Logigian EL, Kelly JJ. Motor neuropathy with multifocal conduction blocks. Muscle Nerve 1989;12:26-31

20. Oh SJ. The "amyotrophic lateral sclerosis form" of chronic inflammatory demyelinating polyneuropathy. Ann Neurol 1990; 28:269 (Abstract) 